\title{
THE WETTABILITY AND SURFACE FREE ENERGY OF SAWN, SLICED AND SANDED EUROPEAN OAK WOOD
}

\author{
Agnieszka Jankowska ${ }^{1, \triangleq}$ Marcin Zbiećl, Pawet Kozakiewicz', Grzegorz Koczan'2, \\ Sylwia Oleńska ${ }^{1}$, Piotr Beer ${ }^{1}$
}

In memoriam of Dr. Thomas C. MANNES

\begin{abstract}
The main objective of this work was to evaluate the effects of two machining processes on European oak wood surface characteristics. The relationships between wettability, free surface energy and machining methods were studied. Sawing and slicing, with or without sanding, were used to prepare surfaces prior to testing whether they produce surfaces with different characteristics. For the wood surfaces machined by slicing and sawing, there was a significant difference in contact angle measurements. This indicates that the influence of machining processes such as slicing and sawing on contact angle value is remarkable. Sanded surfaces showed good wettability and high process roughness.
\end{abstract}

Keywords: Contact angles, Quercus robur, sawing, surface roughness, wood machining.

\section{INTRODUCTION}

In the industrial production process, the occurrence of faults in processing is unavoidable. However, as long as the quality deviations are within certain limit values, then the detail is considered to have been properly processed in context of technological requirements. However, it often happens that the dimensions of the detail are within the limit values, and the details vary in the quality of the machined surface. As is well known, mechanical treatments change the chemical and morphological characteristics of solid surfaces (Liptáková and Kúdela 1994), with the types of machining along with the characteristics of the raw material, or a combination of both these parameters, determining the surface quality and influencing the cost (Kilic et al. 2006, Mitchell and Lemaster 2002).

Sanding is the most common and most influential operation for achieving surface quality during the phase of surface preparation. Wood sanding produces a superficial layer of crushed cells with obstructed lumens, which precludes the coating penetration into the wood surface capillaries, principally through rays. Fine sanding may also generate an accumulation of dust into lumens, likewise hindering penetration (De Meijer et al. 1998, Qin et al. 2015). However, crushed and raised cells produced by sanding (or planing) seem to improve the performance of stains, due to avoiding over-penetration in earlywood tissue, and providing sufficient finish penetration in dense latewood zones. Moreover,

\footnotetext{
${ }^{1}$ Assistant Professor at Department of Wood Sciences and Wood Protection, Faculty of Wood Technology, Warsaw University of Life Sciences. Warsaw, Poland.

${ }^{2} \mathrm{PhD}$ candidate at Department of Wood Sciences and Wood Protection, Faculty of Wood Technology, Warsaw University of Life Sciences. Warsaw, Poland.

•Corresponding author: agnieszka_jankowska@sggw.pl

Received: 30.10.2017 Accepted: 28.02. 2018.
} 
sanding homogenises the surface and reduces the influence of the wood's anatomical characteristics on coating behaviour. Thus, surface damage possibly contributes to a homogeneous spread and penetration of the stain (Richter et al. 1995).

Besides the physical, mechanical, and anatomical properties of wood, the surface quality of finished products is influenced by numerous factors such as: the direction of slicing, the geometry of the blade and its sharpness, the thickness of the cut part, any lack of precision of the sharpening tool as well as the technological parameters (speed of slicing, speed of movement, etc.) (Richter et al. 1995). The surface roughness affects the wetting characteristics of a solid. An increase in surface roughness is often associated with an increase in surface wettability (Arnold 2010). Previous studies have suggested that increased roughness accelerates liquid spreading. The quality of processing includes the quality of the machined surface. A full understanding of the wood surface and wood material provides mostly technical information in solving problems such as capabilities of gluing, impregnation, strength of joints, control of blade sharpness, as well as decrease of waste (Keturakis et al. 2007). Studies show that smooth surfaces require a relatively small amount of paint for surface protection (Marian et al. 1958). Surface roughness is strongly and directly linked or influenced by the future usage condition, making it crucial in flooring production, especially in case of glue laminated floorboards. An effective control of surface roughness is important in production processes related to the adhesive bonding of wood elements and the final processing of finished products (Lemaster et al. 1982). The importance of managing raw materials saving and reducing production costs have forced currently used machining methods to be modified and new solutions to be developed, such as replacing sawing by more wasteless (chipless) technology like slicing. It can give more efficient production by reducing the amount of waste during the production process. Cutting conditions clearly affect the cutting energy, cutting forces and consequently the quality of wood surface (Aguilera and Muñoz 2011, Aguilera and Zamora 2009, Thoma et al. 2015). Thus, knowledge of the effects of different surfacing methods in order to improve the preparation of materials and enhance the coating adhesion is of great interest.

Relatively little research has been made concerning the effects of machining on the wetting characteristics of wood surfaces. Wood of ring porous structure has rarely been tested, with testing of softwood and hardwoods of deciduous porous structure being more common (Gindl et al. 2001, Oberhofnerova and Panek 2016, Qin et al. 2014, Ugulino and Hernandez 2015). The main objective of this work is to evaluate the effects of two machining processes on the wood surface characteristics of European oak (Quercus robur). The relationships between wettability, free surface energy and machining methods are studied. Sawing and slicing (cutting) with or without sanding were used to prepare surfaces prior to testing whether they produce surfaces with different characteristics.

\section{MATERIALS AND METHODS}

\section{Preparation of samples}

Typical European oak (Quercus robur L.) was chosen as the species, because it is widely used in the European wood industry for the production of floors, both from solid wood and glue laminated wood. It was round wood - six logs of WC01 class (according to Polish standards PN-EN 13161:2013-04) and of a lower diameter of 25-34 cm. The wood was derived from Polish forest managed by The State Forests National Forest Holding. The plantation is located in the Lubowo Forest District $\left(53^{\circ} 57^{\prime} 18^{\prime \prime} \mathrm{N}, 16^{\circ} 35^{\prime} 20^{\prime \prime} \mathrm{E}\right)$. The wooden logs were cut to dimensions $120 \times 200 \times 2300 \mathrm{~mm}$. The oak beams were graded into two groups: one to sawing on thin lamellas (thickness of about $4 \mathrm{~mm}$ ) and the other to a flat slicing process. The oak beams were plasticised before sawing and slicing by thermohydro treatment. The thermo-hydro treatment process included: $5 \mathrm{~h}$ of heating up to a temperature of $60{ }^{\circ} \mathrm{C}, 42 \mathrm{~h}$ of thermo-hydro treatment at a temperature of $90^{\circ} \mathrm{C}, 1 \mathrm{~h}$ of cooling down to a temperature of $60{ }^{\circ} \mathrm{C}$. Moisture content of wood during sawing was $70-80 \%$ The sawing process was done on an automated band saw - a Wintersteiger DSB Twinhead NG. The flat slicing process was carried out on a FEZER Lumber Slicer FM 30 cutter adapted for this purpose. The wood was sliced flat to a thickness of about $4 \mathrm{~mm}$. Slicing speed was 100 $/$ min. Drying was carried out in a Vanicek 25 dryer. After drying 
moisture content of wood sawn and sliced was $7-8 \%$. After drying, the surface of half of the sawn lamellas and half of the sliced lamellas were sanded at the end. The sanding was done in two steps; during the first step, abrasive paper with a granulation of 40 was used, while the second step used a granulation of 60 . The feed rate during sanding was $12 \mathrm{~m} / \mathrm{min}$.

The research was carried out on samples obtained as a result of:

1. sawing,

2. sawing and sanding,

3. flat slicing process,

4. flat slicing process and sanding.

\section{Contact angle measurement}

The contact angle is defined as the angle between the solid surface and a tangent, drawn on the drop-surface, passing through the triple-point atmosphere-liquid-solid (Zisman 1963). The contact angles of expanding droplets, i.e. advancing angles, were determined using a contact angle measuring device. Surface properties were determined using the Owens - Wendt methods (Owens and Wendt 1969) with Petrič and Oven recommendations (Petrič and Oven 2015) on a Goniometr Haas Phoenix 300 contact angle analyser connected to computer-dedicated proper software giving the image of a drop on tested wood surfaces. An image analysis system calculated the contour of the drop from an image captured using a video camera. The definition of the contact angle $(\Theta)$ is given in Figure 1. The measurements of the contact angle were taken for each of the ten drops of the liquid placed on ten wood samples. Radial and tangential cross-sections were investigated separately.

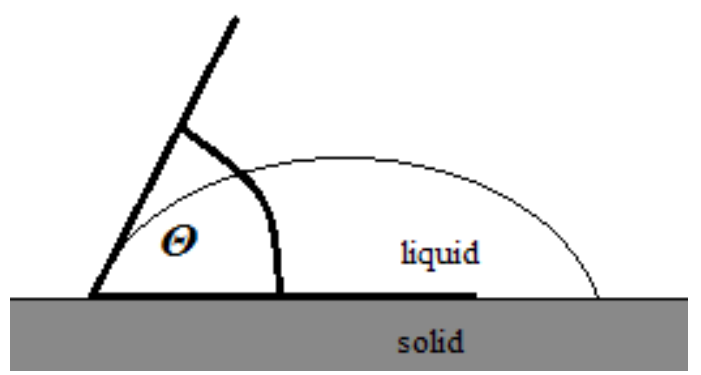

Figure 1. Definition of contact angle $\Theta$ between tested wood surface and liquids.

Table 1. Data for surface tension and the components of the test liquids (Van Oss et al. 1998).

\begin{tabular}{|c|c|c|c|}
\hline \multirow{2}{*}{ Liquid } & \multicolumn{3}{|c|}{ Surface tension } \\
\cline { 2 - 4 } & Total & Dispersion part & Polar part \\
\cline { 2 - 4 } & $\mathbf{m N} / \mathbf{m}$ & \multicolumn{2}{|c|}{$\mathbf{m J} \mathbf{m}^{2}$} \\
\hline $\begin{array}{c}\text { Diodomethane } \\
\left(\mathrm{CH}_{2} \mathrm{I}_{2}\right)\end{array}$ & 50,80 & 50,80 & 0,00 \\
\hline $\begin{array}{c}\text { Formamide } \\
\left(\mathrm{CH}_{3} \mathrm{NO}\right)\end{array}$ & 58,00 & 39,00 & 19,00 \\
\hline $\begin{array}{c}\text { Water } \\
\left(\mathrm{H}_{2} \mathrm{O}\right)\end{array}$ & 72,80 & 21,90 & 51,00 \\
\hline
\end{tabular}

The contact angle was calculated as the average of both sides of the droplets, in order to compensate for any horizontality variations. The initial contact angles recorded immediately after droplet deposition were used to estimate the wood surface energies using Berthelot's combining rule 
(Kwok and Neumann 2000). The testing liquids were distilled water, formamide, and diiodomethane (Table 1). All the chemicals were analytical reagent grade products of Chempur, Poland.

\section{Determination of surface free energy components}

Many methods have been developed to calculate the surface free energy of wood. The acid-based approach is considered to be the most effective method for calculating the surface free energy of wood composites surface tension components (Gindl et al. 2001, Qin et al. 2014).

The re-distilled water and diiodomethane were used as reference liquids for the free surface energy calculations. In this work, the surface free energy was calculated on the basis of formulas established on Young's equations by Owens - Wendt:

$$
\begin{array}{r}
\gamma_{s}=\gamma_{s}^{d}+\gamma_{s}^{p} \\
\left(\gamma_{s}^{d}\right)^{0,5}=\frac{\gamma_{d}\left(\cos \Theta_{d}+1\right)-\sqrt{\frac{\gamma_{d}^{p}}{\gamma_{w}^{p}} \gamma_{w}\left(\cos \Theta_{w}+1\right)}}{2\left(\sqrt{\gamma_{d}^{d}}-\sqrt{\gamma_{d}^{p} \frac{\gamma_{w}^{d}}{\gamma_{w}^{p}}}\right)} \\
\left(\gamma_{s}^{p}\right)^{0,5}=\frac{\gamma_{w}\left(\cos \Theta_{w}+1\right)-2 \sqrt{\gamma_{s}^{d} \gamma_{w}^{d}}}{2 \sqrt{\gamma_{w}^{p}}}
\end{array}
$$

where: $\gamma_{s}$-the experimentally determined wood surface free energy, $\gamma_{s}^{d}$ - the dispersed component of wood surface free energy, $\gamma_{s}^{p}$ - the polar component of wood surface free energy, $\gamma_{d}$ - the surface tension of the diiodomethan, $\gamma_{d}^{d}$ - the dispersed component of surface tension of diiodomethan, $\gamma_{d}^{p}-$ the polar component of surface tension of diiodomethan, $\gamma_{w}$ - the surface tension of water, $\gamma_{w}{ }^{d}-$ the dispersed component of surface tension of water, $\gamma^{p}$ - the polar component of surface tension of water, $\Theta_{d}$ - the contact angle between tested wood surface and diiodomethan, and $\Theta_{w}$ - the contact angle between tested wood surface and water.

\section{Image analysis}

After machining the tested samples, images of the surface were obtained at 50x magnification using scanning microscopy. Scanning electron microscope (SEM) micrographs are often used as a qualitative analysis of machined wood surfaces, and can corroborate with surface roughness evaluations (Ugulino and Hernandez 2015). A scanning electron microscope (SEM) FEI QUANTA 200 with analyser EDS EDAX (FEI Company, USA) was used. The operating parameters to visualise the surface were: vacuum $1,30 \mathrm{mBar}$, acceleration voltage $25,0 \mathrm{kV}$; LFD detector, no coating.

\section{Surface roughness determination}

According to DIN 4768:1990, the roughness parameter is the arithmetic mean of the deviations in absolute values of the mean profile. As part of this work, the surface roughness was determined by measuring deviations from the baseline, determined by a cross-sectional observation at the point of greatest width. Analysis values are the average distance from the profile to the mean line over the length of assessment $\left(\mathrm{R}_{\mathrm{a}}\right)$. Measurements were made using a Nikon SMZ 1500 microscope, working in 
reflected light, coupled to a computer using NIS-Elements software. Ten samples were used for each measurement. The sampling length was $1 \mathrm{~mm}$ and the evaluation length was $15 \mathrm{~mm}$.

\section{Statistical procedure}

A statistical analysis of the test results was carried out using Statistica v. 10 software (StatSoft, Inc., Tulsa, OK, USA). The data were analysed and provided as the mean \pm standard deviation. To determine the relationship between the tested wood properties, simple regressions were used at the different probability levels. Means-differences comparison tests were made when a significant effect was established at the 0,05 level of significance.

\section{RESULTS AND DISCUSSION}

\section{Differences in wettability}

The different machining process affected surface wettability, as determined by contact measurements. The results of wettability measurements of the surfaces obtained from the chipless technology and in the sawing showed that there were significant differences. The contact angles of test liquids are shown in Table 2. For the wood surfaces machined by slicing and sawing, there was a significant difference in contact angle measurements. This indicates that the influence of the machining processes such as slicing and sawing in contact angle value was remarkable. Differences between contact angle for the tested liquids and the surface subjected and not subjected to sanding were not significant. However, because of the sanding process, the wood surface become smoother and more hydrophilic active groups (hydroxyl groups) were exposed on the surface, so the contact angle of water decreased., the wood flour created from the sanding process caused the water to spread more easily on the wood surface. These results were confirmed by other researchers, who found that smooth surfaces display hydrophilic characteristics (El Abed et al. 2011, Qin et al. 2015). The contact angles for all the tested samples were in the range $59,12^{\circ}$ to $89,64^{\circ}$ for water, in the range $29,61^{\circ}$ to $57,65^{\circ}$ for formamide and in the range $21,61^{\circ}$ to $46,68^{\circ}$ for diiodomethane, which all indicates a high variability between the tested wood samples.

Tangential surfaces showed a higher value of contact angle for water in most of the cases. However, there is no significant difference between the radial and tangential cross section in the case of every tested variety. Differences between radial and tangential surfaces in contact angles were confirmed by Amorim et al. (2013). The results indicated that the radial face presents better wettability with water among tested wood species (the smaller value indicates better wettability of the material). The highest value of contact angle for water was exhibited by sawn and sanded wood surfaces. 
Table 2. Contact angles of different machined wood samples.

\begin{tabular}{|c|c|c|c|c|}
\hline \multirow[b]{2}{*}{ Sample } & \multirow[b]{2}{*}{ Surface } & \multicolumn{3}{|c|}{ Contact angles $\left({ }^{\circ}\right)^{*}$} \\
\hline & & $\begin{array}{c}\text { Water } \\
\Theta \\
\Theta\end{array}$ & $\begin{array}{c}\text { Formamide } \\
\Theta_{f}\end{array}$ & $\begin{array}{c}\text { Diiodomethane } \\
\Theta\end{array}$ \\
\hline \multirow{2}{*}{ Sawn } & Radial & $85,12(1,95)$ & $57,65(5,56)$ & $36,15(5,01)$ \\
\hline & Tangential & $89,64(5,45)$ & $59,01(5,39)$ & $40,29(4,79)$ \\
\hline \multirow{2}{*}{ Sawn and sanded } & Radial & $80,12(7,12)$ & $47,56(5,57)$ & $46,68(4,89)$ \\
\hline & Tangential & $86,56(2,52)$ & $55,52(4,43)$ & $30,91(6,76)$ \\
\hline \multirow{2}{*}{ Cut } & Radial & $60,51(7,94)$ & $38,81(4,50)$ & $22,15(2,15)$ \\
\hline & Tangential & $74,19(6,70)$ & $42,15(3,91)$ & $21,61(1,69)$ \\
\hline \multirow{2}{*}{ Cut and sanded } & Radial & $59,12(4,28)$ & $29,61(3,11)$ & $20,44(1,66)$ \\
\hline & Tangential & $60,43(4,67)$ & $34,32(3,42)$ & $25,51(2,84)$ \\
\hline
\end{tabular}

* means and standard deviations in parentheses.

The differences of contact angle for diiodomethane and formamide on the wood surface were also significant. In addition, it was demonstrated again that formamide is a strong hydrogen bonding liquid that radically reduces interfacial free energy at the solid-liquid interface through acid-base interactions (Stehr et al. 2001, Qin et al. 2014). This is the reason why the contact angle was much smaller than that of water. Because diiodomethane is an polar liquid with low surface tension (Van Oss et al. 1998), the contact angles were much smaller than those for water. Comparison tested wood surfaces showed that the contact angle for the test liquids used is always the highest on the sawn samples.

As is well known, surface roughness is an important characteristic in terms of surface quality and properties, particularly in the case of finishing treatments (Buyuksari et al. 2011). The effect of surface roughness parameters $\left(\mathrm{R}_{\mathrm{a}}\right)$ on the contact angles of water are shown in Figure 2. A regression analysis was carried out in order to verify the existence of a relationship between surface roughness and wood wettability, as well as free surface energy. According to this analysis, the correlation between these properties was poor (Table 3). It was difficult to find a relationship between the change in contact angles for the tested liquids and the surface roughness parameter. Compared with surface roughness, the effect of the machining process on contact angle with diiodomethane was more significant than in other cases. In a previous study, this problem had not yet been solved. It can be concluded that it is possible that under the study conditions, roughness did not influence the wettability tested wood samples subjected to different machining. Shupe et al. (2001) and Amorim et al. (2013) stated the same after studying the wettability of sanded and non-sanded surfaces of over thirty wood species. On the other hand, our results allow the conclusion to be drawn that the contact angle is lower when roughness (value of $\mathrm{R}_{\mathrm{a}}$ parameter) is higher and, consequently, that wood wettability is higher, as was presented in Figure 2. The same inference was made by Arnold (2010), who tested differently machined solid wood surfaces regarding surface properties and coating performance.

The results of several dozen measurements of surface inequalities indicate significant differences between surfaces subjected to different machining. The surface of sawn wood is considerably smoother - the largest deviations from the "flatness" were $296 \mu \mathrm{m}$. The "flatness" deviations for the sliced wood were much larger, even close to $1 \mathrm{~mm}$. An analysis of mean values allows us to conclude that, in the case of sliced wood, the difference between the samples presenting tangential and radial sections was significant. 


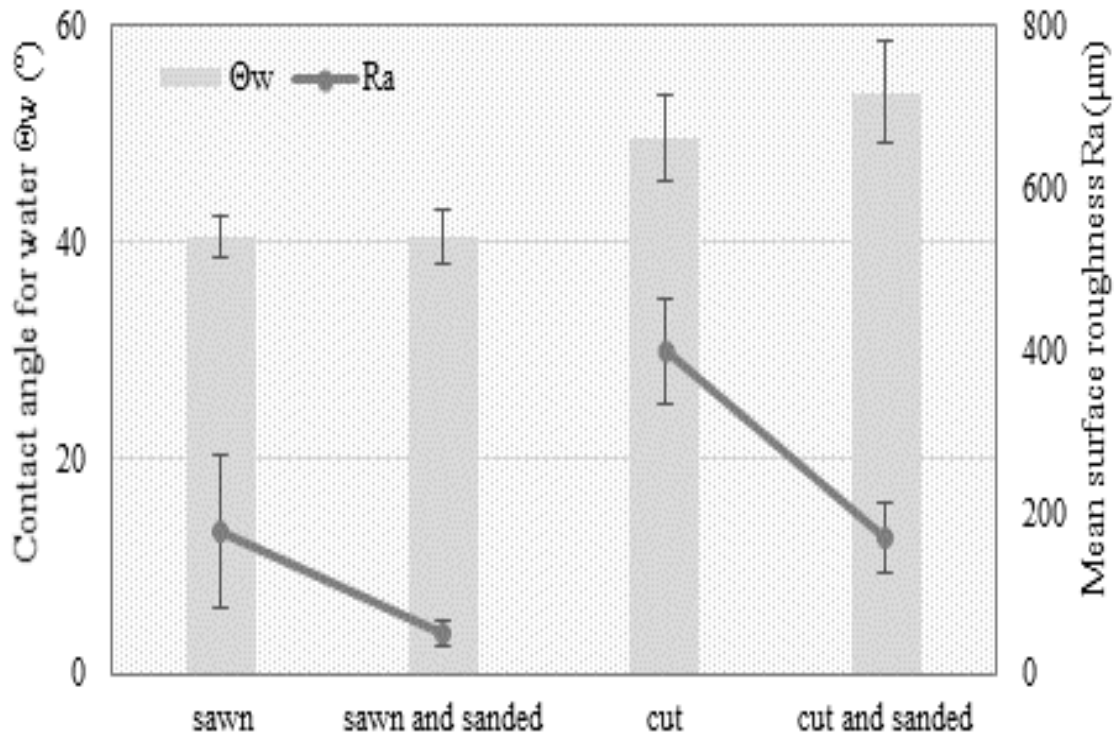

Figure 2. Contact angles and surface roughness of different machined wood samples.

Table 3. Correlation coefficients between surface properties and roughness.

\begin{tabular}{|c|c|c|c|c|c|c|c|}
\hline Variables & $\Theta_{w}$ & $\Theta_{f}$ & $\Theta_{d}$ & $\gamma_{s}^{d}$ & $\gamma_{s}^{p}$ & $\gamma_{s}$ & $R_{a}$ \\
\hline$\Theta_{w}$ & 1,00 & $* *$ & ns & ns & $* *$ & $*$ & ns \\
\hline $\boldsymbol{\Theta}_{f}$ & 0,97 & 1,00 & ns & ns & $* *$ & $* * *$ & ns \\
\hline$\Theta_{d}$ & 0,87 & 0,73 & 1,00 & ns & $\mathrm{ns}$ & $* * *$ & ns \\
\hline$\gamma_{s}^{d}$ & $-0,64$ & $-0,46$ & $-0,89$ & 1,00 & $\mathrm{~ns}$ & ns & $* *$ \\
\hline$\gamma_{s}^{p}$ & $-0,97$ & $-0,96$ & $-0,82$ & 0,67 & 1,00 & $* * *$ & ns \\
\hline$\gamma_{s}$ & $-0,99$ & $-0,94$ & $-0,92$ & 0,69 & 0,95 & 1,00 & ns \\
\hline$R_{a}$ & $-0,45$ & $-0,27$ & $-0,72$ & 0,96 & 0,53 & 0,49 & 1,00 \\
\hline
\end{tabular}

significance $<0,05 ; * * *$ - statistical significant value at level of significance $<0,1$; ns - not significant.

SEM micrographs of the surface of different machined wood samples are shown in Figure 3, Figure 4. As is shown, the roughest and most damaged surface is in the case of sliced wood. The sliced wood subjected to sanding exhibited a much higher quality of surface due to a reduction in roughness (Figure 2). It can be clearly seen from Figure 2 that the smoothest surface compared with others was the surface of sawn wood subjected to sanding. 


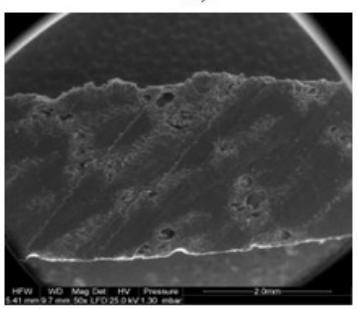

c)

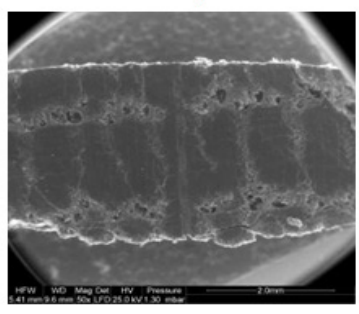

b)

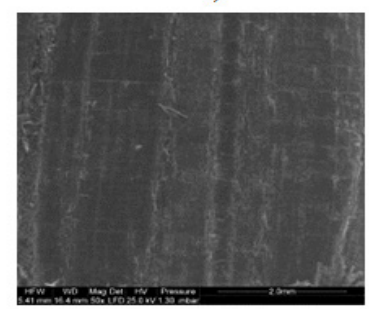

d)

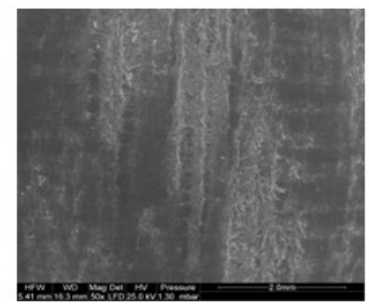

Figure 3. SEM micrographs of different machined wood samples on different wood section: cross and longitudinal transverse of (a-b sawn wood with radial surface, $c-d$ sawn and sanded wood with tangential surface)

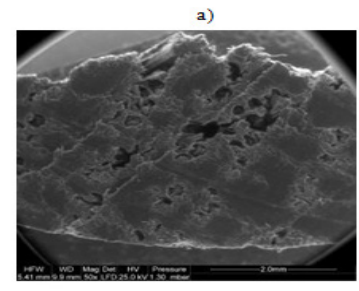

c)

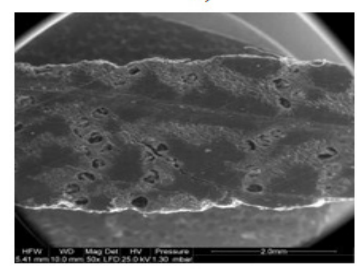

b)

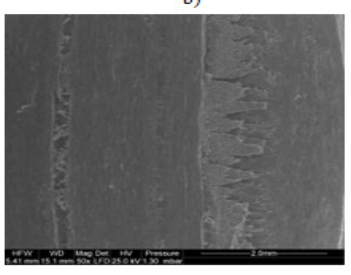

d)

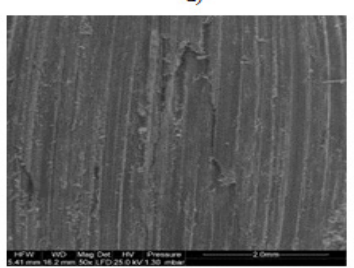

Figure 4. SEM micrographs of different machined wood samples on different wood section: cross and longitudinal transverse (a-b sliced wood with radial surface, $c-d$ sliced and sanded wood with radial surface).

The surfaces morphology of wood was analysed thanks to microscopic images (Figure 3, Figure 4). In case of sliced wood only a few cell wall fibrillations roughed the surface. In the case of sawn wood and sanded wood, several vessels and fibres made the surface rough. Both during sawing and sanding, the wood fibers and other cellular elements were torn out, mechanically destroyed and even crushed. Moreover, sliced wood exhibited several cracks and some delamination, which were smoothed and partially reduced due to sanding. Based on above, it can be confirmed importance of surface quality. Additionally, differences in surfaces different machined wood were showed. 


\section{Differences in the free surface energy of tested material}

The total surface free energy of wood, dispersion and polar components were calculated using the Owens - Wendt method. The results are presented in Table 4. Generally, it can be concluded that cut surfaces (both sanded and not sanded) showed higher surface energy.

Table 4. Mean surface free energy comparisons performed on the data of surface energy components.

\begin{tabular}{|l|l|c|c|c|}
\hline \multirow{2}{*}{ Sample } & \multirow{2}{*}{ Surface } & \multicolumn{3}{|c|}{ Surface free energy $\left(\mathbf{m J} / \mathbf{m}^{\mathbf{2}}\right)$} \\
\cline { 3 - 5 } & & $\begin{array}{c}\text { Polar component } \\
\boldsymbol{\gamma}_{s}^{p}\end{array}$ & $\begin{array}{c}\text { Dispersed } \\
\text { component } \\
\boldsymbol{\gamma}^{\boldsymbol{d}}\end{array}$ & $\begin{array}{c}\text { Total surface free } \\
\text { energy } \\
\boldsymbol{\gamma}_{s}\end{array}$ \\
\hline \multirow{2}{*}{ Sawn } & Radial & 39,47 & 2,03 & 41,49 \\
\cline { 2 - 5 } & Tangential & 38,37 & 2,16 & 39,53 \\
\hline \multirow{2}{*}{ Sawn and sanded } & Radial & 31,97 & 5,18 & 37,14 \\
\cline { 2 - 5 } & Tangential & 42,63 & 6,29 & 43,92 \\
\hline \multirow{2}{*}{ Sliced } & Radial & 39,19 & 12,34 & 51,53 \\
\cline { 2 - 5 } & Tangential & 43,03 & 14,83 & 47,86 \\
\hline \multirow{2}{*}{ Sliced and sanded } & Radial & 39,43 & 13,02 & 52,44 \\
\cline { 2 - 5 } & Tangential & 39,75 & 15,51 & 55,29 \\
\hline
\end{tabular}

The highest total surface energy was observed on sanded surfaces. Sanding increases the free surface energy of the flat cut surface due to structural changes (Qin et al. 2015). As previously reported, sanded surfaces are more uniform because of the combination of cellular damage and dust filling the lumens (Gurau et al. 2005). After sanding flat cut surfaces, the increased surface free energy may be due to the active functional groups exposed (i.e. hydroxyl groups), which caused the surface to become more hydrophilic (Qin et al. 2015). Sanded surfaces had the highest value of disperse component. Similar results were obtained by Qin et al. (2015) after testing fast grown poplar wood.

In order to verify the existence of a relationship between free surface energy and roughness, a simple regression analysis was carried out. According to these studies, the correlation between these properties was rather low (Table 3). Only the dispersed component of surface free energy revealed significant correlation with surface roughness (correlation coefficient was 0,96 ). According to Garnier and Glasser (1996), the dispersed component in cellulosic materials depends mostly on the presence and concentration of free hydroxyl groups on the surface. The microfibrils detached from cell walls can increase the amount of the hydroxyl groups available on surfaces. Thus, the higher value of the disperse component on sanded surfaces could be due to an increase in hydroxyl sites exposed at the surface. A more important polar component is related to hydrophilic surfaces (Gindl et al. 2004). Surfaces prepared by sanding and oblique slicing presented values significantly higher in this component, which agrees with the findings of wetting behaviour.

\section{CONCLUSIONS}

Based on the results of the research conducted, it can be concluded that for the wood surfaces machined by slicing and sawing, there was a significant difference in contact angle measurements. It indicates that the influence of machined processes such as slicing and sawing in contact angle value was remarkable. Sanded surfaces showed good wettability. The contact angle is lower when roughness is higher, thus wood wettability is higher.

There was a significant distinction of value of free surface energy obtained for sawn and cut wood. It indicates that machining is an important indicator determining finishing or gluing. The obtained 
results and analysis of microscopic images allow concluding that sanding increases the free surface energy of the flat cut surface due to structural changes of wood. In case of sawn surfaces as well as sawn and sanded surface the differences in wood structure were not be observed, thus there was no differences in the free surface energy.

\section{ACKNOWLEDGEMENTS}

The presented research was co-financed by The National Centre for Research and Development (NCBR) under Strategic research and development programme "Environment, agriculture and forestry"BIOSTRATEG, project NR IOSTRATEG2/298950/1/NCBR/2016.

\section{REFERENCES}

Aguilera, A.; Muñoz, H. 2011. Rugosidad superficial y potencia de corte en el cepillado de Acacia melanoxylon y Sequoia sempervirens. Maderas-Cienc Tecnol 13 (1): 19-28.

Aguilera, A.; Zamora, R. 2009. Surface roughness in sapwood and heartwood of Blackwood (Acacia melanoxylon R. Br.) machined in 90-0 direction. European Journal of Wood Products 67: 297301 .

Amorim, M.R.S.; Ribeiro P.G.; Martins, S. A.; Del Menezzi, C.H.S.; Souza, M. R. 2013. Surface Wettability and Roughness of 11 Amazonian Tropical Hardwoods. Floresta e Ambiente 20 (1): 99-109.

Arnold, M. 2010. Planing and Sanding of Wood Surfaces - Effects on Surface Properties and Coating Performance. In: Proceedings PRA's $7^{\text {th }}$ International Woodcoatings Congress; Middlesex: Hampton.

Buyuksari, U.; Akbulut, T.; Guler, C.As.N. 2011. Wettability and surface roughness of natural and plantation-grown narrow-leaved (Fraxinus angustifolia Vahl.) wood. BioResources 6: 4721-4730.

De Meijer M.; Thurich K.; Militz H. 1998. Comparative study on penetration characteristics of modern wood coatings. Wood Science and Technology 32 (5): 347-365.

DIN 4768:1990. Determination of values of surface roughness parameters Ra. Rz, Rmax using electrical contact (stylus) instruments concepts and measuring conditions.

El Abed, S.; Ibnsouda, K.S.; Latrache, H.; Boutahari, S. 2011. Theoretical effect of cedar wood surface roughness on the adhesion of conidia from Penicillium expansum. Annals of Microbiology 62 (4): 1361-1366. DOI: 10.1007/s13213-011-0384-5

Gardner, D.J.; Generalla, N.C.; Gunnells, D.W.; Wolcott, M.P. 1991. Dynamic wettability of wood. Langmuir 7 (11): 2498-2502.

Garnier, G.; Glasser, W. G. 1996. Measuring the surface energies of spherical cellulose beads by inverse gas chromatography. Polymers Engineering and Science 36 (6): 885-894.

Gindl, M.; Sinn, G.; Reiterer, A.; Tschegg, S. 2001. Wood Surface Energy and Time Dependence of Wettability:A Comparison of Different Wood Surfaces Using an Acid-BaseApproach. Holzforschung 55: 433-440.

Gindl, W.; Schoberl, T.; Jeronimidis, G. 2004. The interphase in phenol-formaldehyde and 
polymeric methylene diphenyl-di-isocyanate glue lines in wood. International Journal Adhesion Adhesives 24 (4): 279-286.

Gurau, L.; Mansfield-Williams, H. Irle, M. 2005. The influence of wood anatomy on evaluating the roughness of sanded solid wood. Journal of Institute of Wood Science 17 (2): 65-74.

Keturakis, G.; Juodeikienė, I.; 2007. Investigation of milled wood surface roughness. Materials Science (Medžiagotyra) 13 (1): 47-51.

Kilic, M.; Hiziroglu, S.; Burdurlu, E. 2006. Effect of machining on surface roughness of wood. Building and Environment 41: 1074-1078.

Kwok, D. Y.; Neumann, A. W. 2000. Contact angle measurements and contact angle interpretation: relevance to the thermodynamics of adhesion. In Acid-base interactions: relevance to adhesion science and technology, vol. II. Utrecht, Holland. Pp. 91-166.

Lemaster, R.; Dornfeld, D. 1982. Measurement of surface quality of sawn and planed surfaces with a laser. Paper presented in the Seventh Wood Machining Seminar. October 18-20, University of California, Forest Products Laboratory, Richmond, CA, pp 54-61.

Liptáková, E.; Kúdela, J. 1994. Analysis of the wood-wetting process. Holzforschung 48 (2): 139-144.

Marian, J. E.; Stumbo, D. A.; Maxey, C. W. 1958. Surface texture of wood as related to glue joint strength. Forest Products Journal 8: 345-351.

Mitchell, P.; Lemaster, R. 2002. Investigation of machine parameters on the surface quality in routing soft maple. Forest Products Journal 52 (6): 85-90.

Oberhofnerova, E.; Panek, M. 2016. Surface wetting of selected wood species by water during initial stages of weathering. Wood research 61 (4): 545-552.

Owens, D. K.; Wendt, R. C. 1969. Estimation of the surface free energy of polymers. Journal of Applied Polymer Science 13(8): 1741-1747.

Petrič, B.; Oven, P. 2015. Determination of wettability of wood and its significance in wood science and technology: a critical review. Reviews and adhesion and adhesives 3 (2): 121-187.

PN-EN. 2013. Hardwood round timber. Qualitative classification. Oak and beech. PN-EN 13161:2013-04

Qin, Z.; Hui, C.; Qiang, G.; Shifeng, Z.; Jianzhang, L. 2015. Wettability of Sanded and Aged Fast-growing Poplar Wood Surfaces: I. Surface Free Energy. BioResources 9 (4): 7176-7188.

Qin, Z.; Gao, Q.; Zhang, S.; Li J. 2014. Surface Free Energy and Dynamic Wettability of Differently Machined Poplar Woods. BioResources 9 (2): 3088-3103.

Richter, K.; Feist, W. C.; Knaebe, M. T. 1995. The effect of surface roughness on the performance of finishes. Part 1. Roughness characterization and stain performance. Forest Products Journal 45(7/8): 91-97

Shupe, T.F.; Hse, C.Y.; Wang, W.H. 2001. An investigation of selected factors that influence hardwood wettability. Holzforschung 55 (5): 541-548.

Stehr, M.; Gardner, D. J.; Walinder, M. E. P. 2001. Dynamic wettability of different machined wood surfaces. The Journal of Adhesion 76 (3):185-200. DOI: 10.1080/00218460108029625 
Thoma, H.; Peri, L.; Lato, E. 2015. Evaluation of wood surface roughness depending on species characteristics. Maderas-Cienc Tecnol 17 (2): 285-292.

Ugulino B.; Hernández R. E. 2015. Effects of four surfacing methods on surface properties and coating performance of red oak wood. Proceedings of the 22nd International Wood Machining Seminar June 14-17, 2015 Quebec City, Canada

Van Oss, C. J.; Good, R. J.; Chaudhury, M. K. 1998. Additive and nonadditive surface tension components and the interpretation of contact angles. Langmuir 4 (4), 884-891.

Zisman, W. A. 1963. Influence of constitution on adhesion. Industrial \& Engineering Chemistry 55 (10): 18-38. 